\title{
Hemostatic Alterations in Liver Disease: A Review on Pathophysiology, Clinical Consequences, and Treatment
}

\author{
Ton Lisman $^{\mathrm{a}, \mathrm{b}}$ Frank W.G. Leebeek ${ }^{\mathrm{c}}$ \\ a Department of Clinical Chemistry and Haematology, University Medical Centre Utrecht, Utrecht, \\ ${ }^{b}$ Surgical Research Laboratory, Department of Surgery, University Medical Centre Groningen, Groningen, and \\ 'Department of Hematology, Erasmus University Medical Center, Rotterdam, The Netherlands
}

\section{Key Words}

Primary hemostasis $\cdot$ Secondary hemostasis $\cdot$ Fibrinolytic system $\cdot$ Hemostatic dysbalance $\cdot$ Hemostasis testing $\cdot$ Hemostatic abnormalities

\begin{abstract}
In most patients with acute or chronic liver failure, extensive changes in all pathways contributing to hemostasis are found. These hemostatic alterations concern both pro- and antihemostatic pathways, and therefore the net result of the hemostatic dysbalance is unclear. Although it is generally believed that patients with liver disease have a hemostasisrelated bleeding tendency, this concept is challenged in recent literature. Although the bleeding problems in patients with liver disease are obvious, the clinically most relevant bleeding episodes, i.e., bleeding from ruptured varices or ulcers, are due to vascular abnormalities and portal hypertension, and not to an abnormal hemostatic system. Moreover, patients with liver disease sometimes experience thrombosis of the portal vein or hepatic artery, which is in part attributed to hypercoagulation. In addition, a substantial part of the patients with liver disease undergoing liver transplantation can nowadays undergo this major surgical procedure, which involves significant hemostatic challenges, without transfusion of blood products. Therefore, the recent debate
\end{abstract}

on the presence of a major hemostatic defect in patients with liver disease seems justified. This paper will review the hemostatic changes that occur in acute and chronic liver failure, and will review hemostasis testing and reversal of coagulopathy in these patients.

Copyright $\odot 2007$ S. Karger AG, Basel

\section{Alterations in Primary Hemostasis}

Multiple alterations in platelet number and function can be found in patients with liver disease. A schematic representation of the formation of a platelet plug in response to vessel wall damage and concomitant collagen exposure is shown in figure 1 .

A mild to moderately reduced platelet count is frequently present in patients with acute or chronic liver failure. An important cause for thrombocytopenia in chronic liver disease is an increased platelet sequestration in the spleen as a result of congestive splenomegaly, which is related to portal hypertension [1]. In patients with advanced cirrhosis, up to $90 \%$ of the platelets can be stored in the spleen. However, even in these patients the peripheral platelet count usually remains only moderately decreased. Alternative mechanisms that explain the reduced platelet count include a reduced production of

\section{KARGER}

Fax +4161306 1234

E-Mail karger@karger.ch

www.karger.com (c) 2007 S. Karger AG, Basel

0253-4886/07/0244-0250\$23.50/0

Accessible online at:

www.karger.com/dsu
Ton Lisman

Surgical Research Laboratory, Department of Surgery, CMC V, Y2144

University Medical Centre Groningen, Hanzeplein 1

NL-9713 GZ Groningen (The Netherlands)

Tel. +31 50361 9028, Fax +31 50363 2796, E-Mail j.a.lisman@chir.umcg.nl 


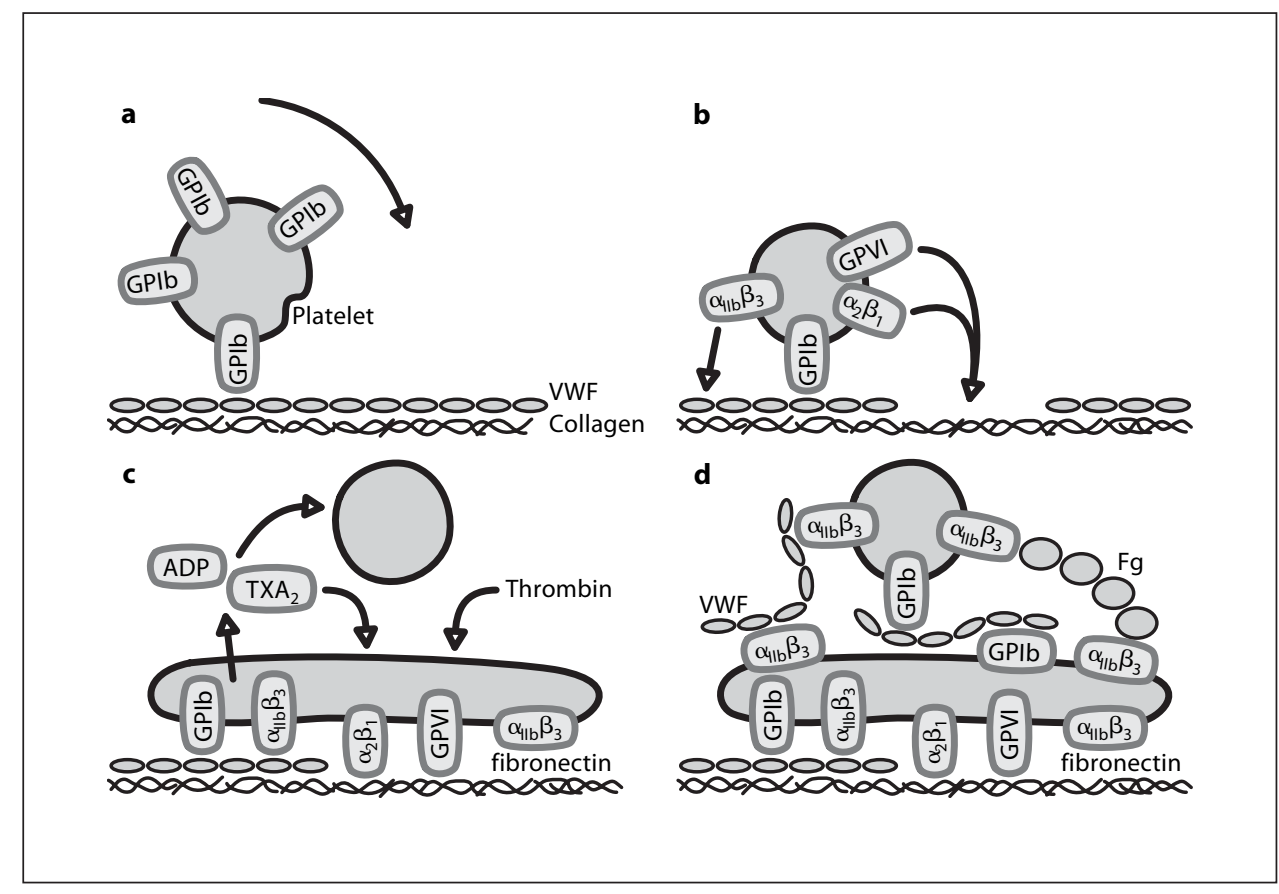

Fig. 1. Schematic representation of platelet adhesion and aggregation under physiological flow conditions. a After vessel wall injury, exposure of collagen and other extracellular matrix proteins initiates recruitment of platelets. The first event leading to platelet deposition is binding of the plasma protein von Willebrand factor (VWF) to the subendothelial collagen. Subsequently, platelets are slowed down at the site of injury by a transient interaction of platelet glycoprotein Ib with collagen-bound VWF. b After the platelets have slowed down by the glycoprotein Ib-VWF interaction, platelets firmly attach to the subendothelial matrix by binding of platelet integrin $\alpha \operatorname{IIb} \beta 3$ to collagen-bound vWF or fibronectin, and platelet receptors $\alpha 2 \beta 1$ and glycoprotein VI to collagen. c Platelets are activated by thrombin formed in the coagulation cascade, and by substances released or synthesized by the platelet, such as $\mathrm{ADP}$ or thromboxane $\mathrm{A}_{2}$. Activation of the platelet results in activation of the aggregation receptor $\alpha \operatorname{IIb} \beta 3$. d Finally, platelet-platelet interaction, mediated by VWF or fibrinogen binding to $\alpha \mathrm{IIb} \beta 3$ on two adjacent platelets, results in the formation of a platelet aggregate. thrombopoietin by the diseased liver [2], a reduced platelet half-life possibly related to autoantibodies [3], and, in patients with alcohol-induced cirrhosis, defective platelet production as a consequence of folic acid deficiency or toxic effects of ethanol on megakaryocytopoiesis [4]. Platelet consumption resulting from low-grade disseminated intravascular coagulation (DIC) may theoretically contribute to the thrombocytopenic state in these patients, but the presence of DIC in patients with liver disease is controversial [5].

Besides a reduction in circulating platelet numbers, functional platelet defects have also been found. Platelet aggregation in suspension in response to various agonists is impaired in acute and chronic liver failure [6]. Defective platelet function may be a result from an acquired storage pool defect [7], defective transmembrane signal transduction [8], decreased levels of arachidonic acid required for thromboxane $\mathrm{A}_{2}$ production in the membrane [9], and de- creased levels of functional platelet receptors as a consequence of proteolysis by plasmin [10]. Furthermore, the presence of abnormal high-density lipoprotein [11], and a reduced hematocrit [12] may impair platelet function in vivo. Finally, increased production of two important endothelial-derived platelet inhibitors, nitric oxide and prostacyclin, may contribute to defective platelet activation in vivo [13]. However, in a recent study we showed that although in vitro platelet adhesion to subendothelial structures under conditions of flow is substantially reduced, this was fully attributable to the reduced platelet count and reduced hematocrit in these patients [14]. When platelet count and hematocrit were adjusted to normal levels, platelet deposition was not different from controls, and therefore we concluded that the intrinsic platelet defects that have been described in patients with cirrhosis are not relevant under conditions of flow. In line with this, Tripodi et al. [15] demonstrated that the capacity of plate- 


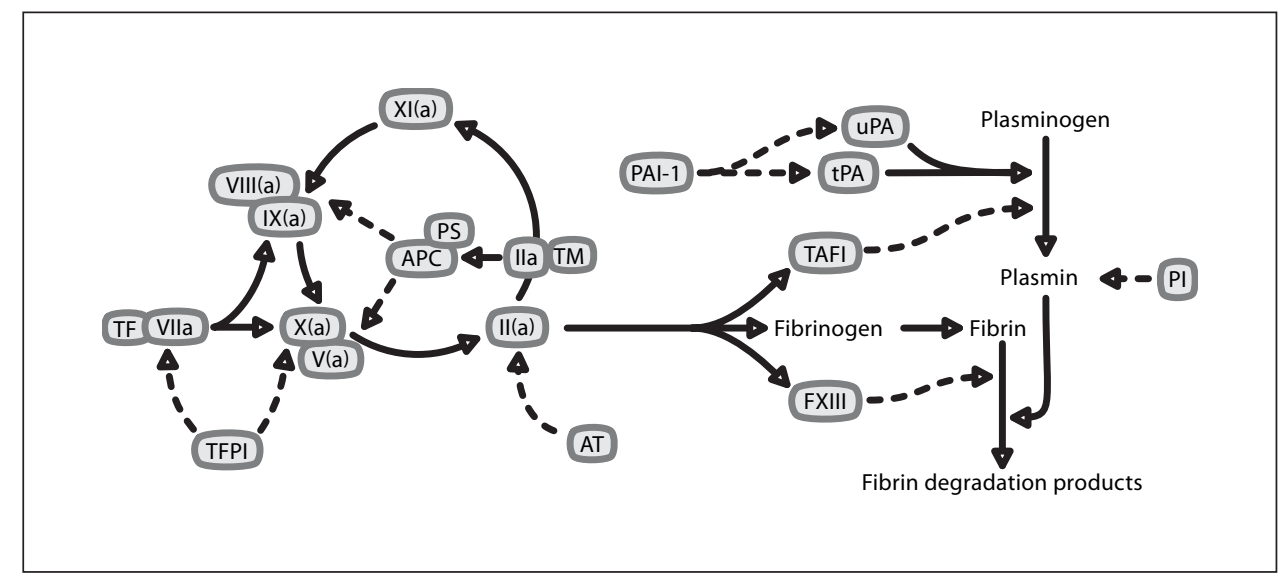

Fig. 2. Processes resulting in the generation and subsequent breakdown of a fibrin clot. In this scheme, activatory processes are indicated by the uninterrupted lines, whereas regulatory or inhibitory steps are indicated by interrupted lines. After vessel wall damage, the transmembrane protein tissue factor (TF) is exposed to the bloodstream and binding of coagulation factor VII initiates a series of enzymatic reactions in which proenzymes are activated into active forms. This process results in the generation of thrombin (factor IIa), which cleaves fibrinogen into fibrin. Thrombin generation is regulated by tissue factor pathway inhibitor (TFPI) and antithrombin (AT), which inactivate factor VIIa and Xa, and thrombin, respectively. Furthermore, activated protein $\mathrm{C}$, activated by a complex between thrombin and the endothelial cell receptor thrombomodulin (TM), inactivates cofactors Va and VIIIa. The fibrin clot can be broken down by the fibrinolytic system, a process initiated by release of plasminogen

lets from patients with cirrhosis to support thrombin generation is indistinguishable from controls provided the platelet count is adjusted to normal levels.

An important compensatory mechanism for the defects in platelet number and function is the substantially elevated level of von Willebrand factor (VWF), a crucial protein involved in the initial attachment of platelets to a site of injury. The mechanisms for the elevated VWF levels include endothelial damage, possibly related to bacterial infection, and enhancement of VWF protein expression in the diseased liver $[16,17]$. We recently demonstrated that VWF plasma levels can be elevated more than 10 -fold in severe cirrhosis. Moreover, despite subtle functional defects, these extremely high plasma levels of VWF are able to support platelet adhesion under flow conditions substantially better than plasma from healthy volunteers, and therefore to compensate, at least in part, for reduced platelet numbers with a possibly reduced function [18]. activators tPA or uPA from endothelial cells, macrophages, or renal epithelial cells. The plasminogen activators activate plasminogen to form plasmin, an enzyme capable of degrading fibrin into soluble fibrin degradation products. Plasmin generation is regulated by plasminogen activator inhibitor type 1 (PAI-1), which is a direct inhibitor of tPA and uPA, and by plasmin inhibitor (PI), which inactivates plasmin. Furthermore, the fibrin clot is rendered more resistant to plasmin by activated FXIII and by activated thrombin activatable fibrinolysis inhibitor (TAFI), both of which are activated by thrombin generation in the coagulation cascade. Activated factor XIII cross-links fibrin fibers to enhance the stability of the fibrin clot. Activated TAFI cleaves C-terminal lysine and arginine residues from partially degraded fibrin, and as these residues are binding sites for tPA and plasminogen required for fibrin-mediated plasminogen activation, fibrinolysis is slowed down as a result of removal of these amino acids.

\section{Alterations in Secondary Hemostasis}

A schematic representation of the reactions leading to the formation of a fibrin clot is depicted in figure 2 .

The liver is the site of synthesis of all plasma proteins (with the exception of factor VIII) involved in the generation of fibrin. Consequently, reduced levels of coagulation factors V, VII, IX, X, XI, and prothrombin are commonly observed in both acute and chronic liver failure. A proportion of the vitamin K-dependent clotting factors VII, IX, X, and prothrombin may be defective in function as a result of decreased $\gamma$-carboxylation, resulting from vitamin $\mathrm{K}$ deficiency or decreased synthesis of the vitamin K-dependent carboxylase [19].

Fibrinogen levels are found within the normal range in patients with stable cirrhosis, but decreased levels are found in patients with more advanced cirrhosis and in patients with acute liver failure. Furthermore, the circulating fibrinogen in patients with liver disease is func- 
tionally aberrant due to excessive sialic acid content, which leads to impaired fibrin polymerization [20].

Factor VIII levels are frequently found to be elevated in patients with liver failure. Although the liver is presumably the primary site of synthesis of factor VIII, as hemophilia A can be resolved by liver transplantation [21], extrahepatic sites of FVIII synthesis, such as the lung, spleen, and kidney have been described and these alternative pathways may be upregulated in patients with liver disease $[22,23]$. Furthermore, the elevated levels of factor VIII may be related to the elevated levels of its carrier protein VWF, or to the decreased expression of the low-density lipoprotein-related receptor, which is involved in factor VIII clearance [17].

The defects in production of procoagulant proteins is, at least in part, compensated for by decreased production of natural anticoagulant proteins protein $C$, protein $S$, protein $\mathrm{Z}$, protein $\mathrm{Z}$-dependent protease inhibitor, antithrombin, heparin cofactor II, and $\alpha_{2}$-macroglobulin, all of which are synthesized by the liver [24]. Levels of tissue factor pathway inhibitor, which is synthesized by endothelial cells, are normal in patients with liver failure, although one study found decreased levels $[25,26]$.

\section{Alterations in the Fibrinolytic System}

Figure 2 shows the events involved in the breakdown of a fibrin clot. All proteins involved in fibrinolysis, except for tissue-type plasminogen activator (tPA) and plasminogen activator inhibitor 1 (PAI-1), are synthesized by the liver, and indeed reduced levels of plasminogen, plasmin inhibitor, thrombin activatable fibrinolysis inhibitor (TAFI), and factor XIII are found in both acute and chronic liver failure [27-29]. Plasma levels of tPA are elevated due to enhanced release by the activated endothelium and/or by reduced clearance by the diseased liver [30]. PAI-1 levels are also increased, but not to the same extent as tPA levels [31], except in acute liver failure, in which PAI-1 levels are substantially increased [32].

The net effect of the alterations in the fibrinolytic system has been classically described as hyperfibrinolysis [33], except in patients with acute hepatic failure, in which the elevated PAI-1 levels shift the balance to hypofibrinolysis [32].

Reviewing the available literature on fibrinolysis in cirrhosis, we found that the evidence for the well-accepted hyperfibrinolytic state of these patients was in fact rather weak [24,28]. The evidence for a hyperfibrinolytic state in cirrhosis is either derived from in vitro clot ly- sis assays which all suffer from methodological drawbacks, or from elevated plasma levels of indicators of fibrinolysis. However, it is important to realize that indicators of fibrinolysis (or coagulation) such as D-dimers or plasmin-antiplasmin complexes (but also prothrombin fragment $\mathrm{F} 1+2$, fibrinopeptide A, or thrombinantithrombin complexes) are breakdown products, activation peptides, or protease-inhibitor complexes with a relatively short half-life. It is likely that the clearance of these molecules is delayed in patients with liver disease, resulting in false-positive elevated levels. Along the same lines, it has been suggested that hyperfibrinolysis in cirrhosis is secondary to DIC (again diagnosed by measurements of these plasma markers) [34]. However, the absence of fibrin deposition in organs of patients with liver disease, as determined in post-mortem studies, argues strongly against the presence of DIC in these patients [35].

When we assayed overall plasma fibrinolytic potential in a well-defined group of patients with cirrhosis, we found no evidence of hyperfibrinolysis, and therefore postulated that the reduction in antifibrinolytic proteins is balanced by the concomitant reduction in profibrinolytic proteins [28]. Although our assay did not include platelets, which contribute to fibrinolysis by platelet-derived PAI-1, we feel that our hypothesis is supported by the clinical bleeding symptoms of patients with stable liver disease. A typical hyperfibrinolytic bleeding pattern, observed in patients with PAI-1 or antiplasmin deficiency who show delayed bleeding after trauma or surgery, is not present in patients with liver disease. On the other hand, patients with cirrhosis often experience mucosa-associated bleeding, which can also be seen in hyperfibrinolytic states. A recent study challenged our findings [36], and more studies using fibrinolysis assays using whole blood are currently being carried out to resolve this question. In addition, the relationship between fibrinolysis abnormalities and bleeding pattern should be studied more extensively.

\section{Factors Aggravating or Relieving the Hemostatic Dysbalance in Patients with Liver Disease}

It has to be noted that the hemostatic profiles found in patients with liver disease vary with the etiology of the disease. For example, patients with cholestatic disease appear to have a milder hemostatic defect as compared to non-cholestatic liver disease [37]. Furthermore, the hemostatic dysbalance in every type of liver disease can be 
(at least theoretically) ameliorated by the presence of prothrombotic risk factors such as the factor V Leiden mutation, the prothrombin G20210A mutation, or the methylenetetrahydrofolate reductase C677T mutation. In accordance with this theory, patients with these mutations have an increased risk for development of portal, hepatic or mesenteric vein thrombosis [38].

The development of renal failure could potentially aggravate the hemostatic dysbalance of a patient with liver failure. Renal failure itself leads to a bleeding tendency, which is ascribed to a combination of abnormalities in platelet function, abnormal platelet-vessel wall interaction, anemia, and endothelial abnormalities [39].

Another potentially important modulator of hemostasis in patients with liver disease is the presence of bacterial infections. Endotoxemia inhibits platelet function by enhancement of nitric oxide and prostacyclin production, and inhibits coagulation by generation of endogenous heparin-like substances [40]. Furthermore, bacterial infection worsens the hemodynamic state of the patients, which contributes to development of variceal bleeding. However, bacterial infections can also stimulate the coagulation cascade [41].

\section{Do Patients with Liver Disease Have a Bleeding Tendency?}

It is evident that patients with liver disease may have extensive alterations in their hemostatic system. However, it is important to realize that besides defects in prohemostatic systems, defects in anticoagulant systems occur simultaneously. Table 1 summarizes the hemostatic changes either impairing or promoting hemostasis. Recent publications have challenged the well-accepted dogma that liver disease is accompanied by a bleeding tendency [42-45]. One of the reasons why older literature consistently found a decreased coagulation potential and an increased fibrinolytic potential in these patients can be in part explained by the methodology used, in which the anticoagulant and profibrinolytic systems were frequently insufficiently incorporated in the laboratory test. We now believe that the defects in platelet number and function may be balanced by substantially elevated VWF levels (as mentioned above), and the decreased levels of coagulation factors and inhibitors of fibrinolysis, may be balanced by decreased levels of inhibitors of coagulation and profibrinolytic factors. Solid proof of a truly rebalanced hemostasis system in these patients is however still lacking.
Table 1. Hemostatic changes in patients with liver disease that either contribute (A) or counteract (B) bleeding

A Changes that impair hemostasis

Thrombocytopenia

Reduced hematocrit

Platelet function defects (?)

Enhanced production of nitric oxide and prostacyclin

Low levels of coagulation factors II, V, VII, IX, X, and XI

Vitamin K deficiency

Dysfibrinogenemia

Low levels of plasmin inhibitor, factor XIII, and TAFI

Elevated levels of tPA

B Changes that promote hemostasis

Elevated levels of VWF

Elevated levels of factor VIII

Decreased levels of protein $\mathrm{C}$, protein $\mathrm{S}$, and antithrombin

Low levels of plasminogen

The bleeding problems that occur frequently in patients with liver disease are mostly not life-threatening, but are still of concern (e.g., bruising, petechiae, purpura, nose bleeds, and bleeding after dental extractions). However, the clinically most relevant bleeding problems in these patients, bleeding from ruptured esophageal varices, is a consequence of local vascular abnormalities as well as increased splanchnic blood pressure, and the role of deranged hemostasis in variceal bleeding is questionable [46].

One of the most evident hemostatic challenges for a patient with chronic liver failure is liver transplantation. In the past, liver transplantation required extensive blood product transfusion, which was ascribed to pre- and perioperative hemostatic dysfunction. However, nowadays blood loss during transplantation is often rather limited for a procedure with such surgical invasiveness. Transfusion requirements have dropped to a median of 2-3 units of red blood cells in many centers, and a substantial number of patients (up to $50 \%$, depending on the center) are transplanted without the need of any transfusion [47]. Since increasing surgical experience, improvements in surgical techniques, and improvement of anesthesiological care have led to this marked reduction of blood loss during liver transplantation, it has to be concluded that liver disease is not essentially associated with a severe coagulopathic state in this situation. A procedure with these surgical characteristics could never be performed without prophylaxis or transfusion requirements in a patient with an established (classical) coagulopathy, e.g., a pa- 
tient with hemophilia. Nonetheless, there still remain with acute or chronic compensated liver failure patient with severe and refractory bleeding, but it is unclear whether currently used hemostasis testing is capable of identifying these patients.

\section{Hemostasis Testing in Patients with Liver Disease}

The clinical consequences of the mild to moderate reduction in platelet number and function in liver disease are unclear. Although the bleeding time, a diagnostic screening tool of platelet function, is frequently prolonged, a correlation with bleeding symptoms is not necessarily present. The same is true for the classic platelet aggregation assays, which are frequently disturbed in these patients.

Coagulation tests such as the prothrombin time (PT) and activated partial thromboplastin time (APTT) are frequently used in patients with liver failure to assess the severity of the disease. In fact, the PT and PT-INR (the international normalized ratio, a variant of the PT developed to standardize PT values for reagent and equipment for patients on long-term anticoagulant therapy with vitamin $\mathrm{K}$ antagonists) are part of the Child-Pugh and MELD (Model of End stage Liver Disease) scores, respectively.

Two major problems with the use of these tests are not frequently mentioned in the literature. First, although the PT is prolonged in many patients with liver disease, this does not necessarily mean they have a bleeding tendency. This results from the fact that the PT only measures procoagulant factors, and does not take the reduction of anticoagulant factors in these patients into account. In fact, Tripodi et al. [43] showed that when the PT is modified to include anticoagulant factors, thrombin generation in liver disease patients is not different from controls. Secondly, although the INR is an important determinant of the MELD score, the intra-laboratory variability of this assay is substantial in these patients $[48,49]$. In fact, use of the INR instead of the PT increases intra-laboratory variability of the assay, which is not surprising since the INR is only developed and validated for patients on anticoagulation therapy with vitamin $\mathrm{K}$ antagonists. Differences in laboratory methods can give rise to substantial differences in the INR of a given patient and thus can substantially affect a liver transplant candidate's MELD score. Using a reagent which gives rise to a higher INR thus may actually increase the chance of a patient receiving a donor liver.
Thus, the poor performance of this widely used test has major consequences for clinical practice, which is in our opinion insufficiently recognized.

\section{Treatment of Hemostatic Abnormalities in Patients with Liver Disease}

In view of the questionable nature of the severity of the bleeding tendency in patients with liver disease, treatment of coagulopathy should be aimed at reversal of clinically relevant problems instead of reversal of abnormal laboratory values. This strategy is presumably useful, as in patients undergoing liver transplantation, preoperative transfusion to increase platelet count or improve the PT or the bleeding time is no longer clinical practice, and still a substantial amount of patients do not display a severe bleeding tendency during the procedure and can be transplanted without or with minimal transfusion of blood products.

In patients with liver disease undergoing other procedures, a policy to improve platelet count and coagulation parameters prior to the procedure is, however, still common practice. Fresh-frozen plasma (FFP) is frequently administered to patients with a prolonged PT despite a recent transfusion guideline that specifically states: 'available evidence suggests that patients with liver disease and a PT more than $4 \mathrm{~s}$ longer than control are unlikely to benefit from FFP (grade C recommendation, level IV evidence)' [50]. Also it has to be noted that FFP often has an unpredictable response in patients with liver disease, and does often not lead to a complete normalization of the PT or INR [51]. Moreover, transfusion of FFP may be accompanied by side effects such as volume overload and exacerbation of portal hypertension, risk of infection, and risk of transfusion-related acute lung injury. Since the costs of FFP transfusion are high, the possible side effects and the unknown efficacy, we advise against routine prophylactic transfusion of FFP in patients with liver disease and a prolonged PT or INR. Instead one should pursue on demand or rescue therapy when bleeding does occur.

A prolonged bleeding time may be reversed by transfusion of platelet concentrates. However, the clinical relevance of a prolonged bleeding time in these patients is highly questionable. Nonetheless, a prolonged bleeding time was mentioned as an absolute contraindication for liver biopsy in a recent review [52]. We feel, however, that at present no evidence exists for the use of a bleeding time measurement in patients with liver disease prior to a procedure. Should one still choose to perform a bleeding 
time we would argue strongly against prophylactic platelet transfusion to correct a prolonged bleeding time with arguments similar to those stated above for FFP transfusion for a prolonged PT/INR.

Thus, in view of the lack of data supporting prophylactic treatment with FFP or platelet concentrates, we advise to withhold transfusion of these products until clinically relevant bleeding occurs, although this strategy requires validation in clinical studies. These studies are justified by the success of the wait-and-see policy during liver transplantation. Exceptions include very high-risk procedures in which bleeding is unlikely to be detected in time to intervene before irreversible damage occurs (e.g., intracranial pressure monitor placement in patients with acute liver failure). In these circumstances, it seems reasonable to correct prolonged coagulation times, in spite of limited clinical data to support the practice.

Commonly used pharmaceuticals to treat coagulation abnormalities in patients with liver disease include 1-deamino-8-D-arginine vasopressin (DDAVP), antifibrinolytic agents such as aprotinin and tranexamic acid, and recombinant factor VIIa (rFVIIa). Although DDAVP is widely used, and has been shown to correct bleeding time [53], the hemostatic effects in patients with liver disease are questionable. Several studies showed no effect of DDVAP on variceal bleeding or on blood loss in patients undergoing hepatectomy or liver transplantation, indicating that correction of the bleeding time may not necessarily result in improvement of hemostasis [54-56]. The use of antifibrinolytic agents in these patients seems justified in view of the substantial reduction in blood loss in patients undergoing liver transplantation receiving either aprotinin or $\varepsilon$-aminocaproic acid [57, 58]. However, the risk/benefit ratio of aprotinin for other indications has recently been questioned [59]. Finally, rFVIIa was shown to reduce blood loss during liver transplantation [60], but these results were not confirmed in larger randomized studies $[61,62]$. Furthermore, rFVIIa did not reduce blood loss during liver resection, and was it only effective in treatment of variceal bleeding in a subset of patients. The role of rFVIIa for treatment of patients with liver disease therefore remains unclear.

\section{References}

1 Aster RH: Pooling of platelets in the spleen: role in the pathogenesis of 'hypersplenic' thrombocytopenia. J Clin Invest 1966;45: 645-657.

$>2$ Goulis J, Chau TN, Jordan S, Mehta AB, Watkinson A, Rolles K, Burroughs AK: Thrombopoietin concentrations are low in patients with cirrhosis and thrombocytopenia and are restored after orthotopic liver transplantation. Gut 1999;44:754-758.

3 Kajihara M, Kato S, Okazaki Y, Kawakami Y, Ishii H, Ikeda Y, Kuwana M: A role of autoantibody-mediated platelet destruction in thrombocytopenia in patients with cirrhosis. Hepatology 2003;37:1267-1276.

4 Levine RF, Spivak JL, Meagher RC, Sieber F: Effect of ethanol on thrombopoiesis. $\mathrm{Br} \mathrm{J}$ Haematol 1986;62:345-354.

$\checkmark 5$ Ben Ari Z, Osman E, Hutton RA, Burroughs AK: Disseminated intravascular coagulation in liver cirrhosis: fact or fiction? Am J Gastroenterol 1999;94:2977-2982.

-6 Escolar G, Cases A, Vinas M, Pino M, Calls J, Cirera I, Ordinas A: Evaluation of acquired platelet dysfunctions in uremic and cirrhotic patients using the platelet function analyzer (PFA-100): influence of hematocrit elevation. Haematologica 1999;84:614-619.
7 Laffi G, Marra F, Gresele P, Romagnoli P, Palermo A, Bartolini O, Simoni A, Orlandi L, Selli ML, Nenci GG: Evidence for a storage pool defect in platelets from cirrhotic patients with defective aggregation. Gastroenterology 1992;103:641-646.

-8 Laffi G, Marra F, Failli P, Ruggiero M, Cecchi E, Carloni V, Giotti A, Gentilini P: Defective signal transduction in platelets from cirrhotics is associated with increased cyclic nucleotides. Gastroenterology 1993; 105: 148-156.

9 Laffi G, Cominelli F, Ruggiero M, Fedi S, Chiarugi VP, La Villa G, Pinzani M, Gentilini P: Altered platelet function in cirrhosis of the liver: impairment of inositol lipid and arachidonic acid metabolism in response to agonists. Hepatology 1988; 8 1620-1626.

10 Pasche B, Ouimet H, Francis S, Loscalzo J: Structural changes in platelet glycoprotein IIb/IIIa by plasmin: determinants and functional consequences. Blood 1994;83:404414.

11 Desai K, Mistry P, Bagget C, Burroughs AK, Bellamy MF, Owen JS: Inhibition of platelet aggregation by abnormal high density lipoprotein particles in plasma from patients with hepatic cirrhosis. Lancet 1989;1:693695.
12 Turitto VT, Baumgartner HR: Platelet interaction with subendothelium in a perfusion system: physical role of red blood cells. Microvasc Res 1975;9:335-344.

13 Cahill PA, Redmond EM, Sitzmann JV: Endothelial dysfunction in cirrhosis and portal hypertension. Pharmacol Ther 2001;89:273293.

14 Lisman T, Adelmeijer J, de Groot PG, Janssen HL, Leebeek FW: No evidence for an intrinsic platelet defect in patients with liver cirrhosis - studies under flow conditions. J Thromb Haemost 2006;4:2070-2072.

15 Tripodi A, Primignani M, Chantarangkul V, Clerici M, Dell'era A, Fabris F, Salerno F, Mannucci PM: Thrombin generation in patients with cirrhosis: the role of platelets. Hepatology 2006;44:440-445.

- 16 Ferro D, Quintarelli C, Lattuada A, Leo R, Alessandroni M, Mannucci PM, Violi F: High plasma levels of von Willebrand factor as a marker of endothelial perturbation in cirrhosis: relationship to endotoxemia. Hepatology 1996;23:1377-1383.

17 Hollestelle MJ, Geertzen HGM, Straatsburg IH, van Gulik TM, van Mourik JA: Factor VIII expression in liver disease. Thromb Haemost 2004;91;267-275. 
$>18$ Lisman T, Bongers TN, Adelmeijer J, Janssen HL, de Maat MP, de Groot PG, Leebeek FW: Elevated levels of von Willebrand factor in cirrhosis support platelet adhesion despite reduced functional capacity. Hepatology 2006;44:53-61.

19 Blanchard RA, Furie BC, Jorgensen M, Kruger SF, Furie B: Acquired vitamin K-dependent carboxylation deficiency in liver disease. N Engl J Med 1981;305:242-248.

-20 Martinez J, MacDonald KA, Palascak JE: The role of sialic acid in the dysfibrinogenemia associated with liver disease: distribution of sialic acid on the constituent chains. Blood 1983;61:1196-1202.

-21 Bontempo FA, Lewis JH, Gorenc TJ, Spero JA, Ragni MV, Scott JP, Starzl TE: Liver transplantation in hemophilia A. Blood 1987;69:1721-1724.

-22 Hollestelle MJ, Poyck PP, Hollestelle JM, Marsman HA, Mourik JA, Gulik TM: Extrahepatic factor VIII expression in porcine fulminant hepatic failure. J Thromb Haemost 2005;3:2274-2280.

23 Jacquemin M, Neyrinck A, Hermanns MI, Lavend'homme R, Rega F, Saint-Remy JM, Peerlinck K, Van RD, Kirkpatrick CJ: FVIII production by human lung microvascular endothelial cells. Blood 2006;108:515-517.

-24 Lisman T, Leebeek FWG, de Groot PG: Haemostatic abnormalities in patients with liver disease. J Hepatol 2002;37:280-287.

-25 Bajaj MS, Kuppuswamy MN, Saito H, Spitzer SG, Bajaj SP: Cultured normal human hepatocytes do not synthesize lipoprotein-associated coagulation inhibitor: evidence that endothelium is the principal site of its synthesis. Proc Natl Acad Sci USA 1990;87:88698873.

-26 Oksuzoglu G, Simsek H, Haznedaroglu IC, Kirazli S: Tissue factor pathway inhibitor concentrations in cirrhotic patients with and without portal vein thrombosis. Am J Gastroenterol 1997;92:303-306.

$\checkmark 27$ Stein SF, Harker LA: Kinetic and functional studies of platelets, fibrinogen, and plasminogen in patients with hepatic cirrhosis. J Lab Clin Med 1982;99:217-230.

28 Lisman T, Leebeek FW, Mosnier LO, Bouma BN, Meijers JC, Janssen HL, Nieuwenhuis $\mathrm{HK}$, de Groot PG: Thrombin-activatable fibrinolysis inhibitor deficiency in cirrhosis is not associated with increased plasma fibrinolysis. Gastroenterology 2001;121:131-139.

$\checkmark 29$ Biland L, Duckert F, Prisender S, Nyman D: Quantitative estimation of coagulation factors in liver disease. The diagnostic and prognostic value of factor XIII, factor V and plasminogen. Thromb Haemost 1978;39: 646-656.

-30 Leiper K, Croll A, Booth NA, Moore NR, Sinclair T, Bennett B: Tissue plasminogen activator, plasminogen activator inhibitors, and activator-inhibitor complex in liver disease. J Clin Pathol 1994;47:214-217.
31 Leebeek FWG, Kluft C, Knot EAR, de Maat MPM, Wilson JHP: A shift in balance between profibrinolytic and antifibrinolytic factors causes enhanced fibrinolysis in cirrhosis. Gastroenterology 1991;101:13821390.

32 Pernambuco JR, Langley PG, Hughes RD, Izumi S, Williams R: Activation of the fibrinolytic system in patients with fulminant liver failure. Hepatology 1993;18:13501356.

33 Leebeek FWG: Hyperfibrinolysis in liver cirrhosis; in Greenwaldt P (ed): Fibrinolysis in Disease. Boca Raton, CRC Press, 1995, pp 194-201.

34 Violi F, Ferro D, Basili S, Quintarelli C, Musca A, Cordova C, Balsano F, the CALC Group: Hyperfibrinolysis resulting from clotting activation in patients with different degrees of cirrhosis. Hepatology 1993;17:7883.

35 Oka K, Tanaka K: Intravascular coagulation in autopsy cases with liver diseases. Thromb Haemost 1979;42:564-570.

6 Colucci M, Binetti BM, Branca MG, Clerici C, Morelli A, Semeraro N, Gresele P: Deficiency of thrombin activatable fibrinolysis inhibitor in cirrhosis is associated with increased plasma fibrinolysis. Hepatology 2003;38:230-237.

37 Segal H, Cottam S, Potter D, Hunt BJ: Coagulation and fibrinolysis in primary biliary cirrhosis compared with other liver disease and during orthotopic liver transplantation. Hepatology 1997;25:683-688.

38 Amitrano L, Brancaccio V, Guardascione MA, Margaglione M, Iannaccone L, D’Andrea G, Marmo R, Ames PR, Balzano A: Inherited coagulation disorders in cirrhotic patients with portal vein thrombosis. Hepatology 2000;31:345-348.

39 Joist JH, George JN: Hemostatic abnormalities in liver and renal disease; in Colman RW, Hirsh J, Marder VJ, Clowes AE, George JN (eds): Hemostasis and Thrombosis. Philadelphia, Lippincott Williams \& Wilkins, 2001, pp 955-973.

40 Thalheimer U, Triantos CK, Samonakis DN, Patch D, Burroughs AK: Infection, coagulation, and variceal bleeding in cirrhosis. Gut 2005;54:556-563.

41 Reitsma PH, Branger J, Van Den BB, Weijer S, van der PT, Meijers JC: Procoagulant protein levels are differentially increased during human endotoxemia. J Thromb Haemost 2003;1:1019-1023.

42 Caldwell SH, Hoffman M, Lisman T, Macik BG, Northup PG, Reddy KR, Tripodi A, Sanyal AJ: Coagulation disorders and hemostasis in liver disease: pathophysiology and critical assessment of current management. Hepatology 2006;44:1039-1046.
43 Tripodi A, Salerno F, Chantarangkul V, Clerici M, Cazzaniga M, Primignani M, Mannucci PM: Evidence of normal thrombin generation in cirrhosis despite abnormal conventional coagulation tests. Hepatology 2005;41:553-558.

44 Mannucci PM: Abnormal hemostasis tests and bleeding in chronic liver disease: Are they related? No. J Thromb Haemost 2006; 721-723.

45 Lisman T, Caldwell SH, Leebeek FWG, Porte RJ: Hemostasis in chronic liver disease - Is chronic liver disease associated with a bleeding diathesis? J Thromb Haemost 2006; 4: 2059-2060.

46 Sharara AI, Rockey DC: Gastroesophageal variceal hemorrhage. N Engl J Med 2001;345: 669-681.

-47 De Boer MT, Molenaar IQ, Hendriks HG, Slooff MJ, Porte RJ: Minimizing blood loss in liver transplantation: progress through research and evolution of techniques. Dig Surg 2005;22:265-275.

48 Trotter JF, Brimhall B, Arjal R, Phillips C: Specific laboratory methodologies achieve higher model for end-stage liver disease (MELD) scores for patients listed for liver transplantation. Liver Transpl 2004;10:9951000.

49 Robert A, Chazouilleres O: Prothrombin time in liver failure: time, ratio, activity percentage, or international normalized ratio? Hepatology 1996;24:1392-1394

50 O'Shaughnessy DF, Atterbury C, Bolton MP, Murphy M, Thomas D, Yates S, Williamson LM: Guidelines for the use of fresh-frozen plasma, cryoprecipitate and cryosupernatant. Br J Haematol 2004;126:11-28.

51 Youssef WI, Salazar F, Dasarathy S, Beddow T, Mullen KD: Role of fresh-frozen plasma infusion in correction of coagulopathy of chronic liver disease: a dual phase study. Am J Gastroenterol 2003;98:1391-1394.

52 Bravo AA, Sheth SG, Chopra S: Liver biopsy. N Engl J Med 2001;344:495-500.

53 Burroughs AK, Matthews K, Qadiri M, Thomas N, Kernoff P, Tuddenham E, McIntyre $\mathrm{N}$ : Desmopressin and bleeding time in patients with cirrhosis. Br Med J (Clin Res Ed) $1985 ; 291: 1377-1381$.

54 De Franchis R, Arcidiacono PG, Carpinelli L, Andreoni B, Cestari L, Brunati S, Zambelli A, Battaglia G, Mannucci PM: Randomized controlled trial of desmopressin plus terlipressin versus terlipressin alone for the treatment of acute variceal hemorrhage in cirrhotic patients: a multicenter, doubleblind study. New Italian Endoscopic Club. Hepatology 1993;18:1102-1107.

55 Wong AY, Irwin MG, Hui TW, Fung SK, Fan ST, Ma ES: Desmopressin does not decrease blood loss and transfusion requirements in patients undergoing hepatectomy. Can J Anaesth 2003;50:14-20.

56 Pivalizza EG, Warters RD, Gebhard R: Desmopressin before liver transplantation. Can J Anaesth 2003:50:748-749. 
-57 Porte RJ, Molenaar IQ, Begliomini B, Groenland TH, Januszkiewicz A, Lindgren L, Palareti G, Hermans J, Terpstra OT: Aprotinin and transfusion requirements in orthotopic liver transplantation: a multicentre randomised double-blind study. EMSALT Study Group. Lancet 2000;355:1303-1309.

58 Boylan JF, Klinck JR, Sandler AN, Arellano R, Greig PD, Nierenberg H, Roger SL, Glynn MF: Tranexamic acid reduces blood loss, transfusion requirements, and coagulation factor use in primary orthotopic liver transplantation. Anesthesiology 1996;85:10431048.
59 Mangano DT, Tudor IC, Dietzel C: The risk associated with aprotinin in cardiac surgery. N Engl J Med 2006;354:353-365.

60 Hendriks HG, Meijer K, de Wolf JT, Klompmaker IJ, Porte RJ, de Kam PJ, Hagenaars AJ, Melsen T, Slooff MJ, van der Meer J: Reduced transfusion requirements by recombinant factor VIIa in orthotopic liver transplantation: a pilot study. Transplantation 2001;71: 402-405.
61 Planinsic RM, van der MJ, Testa G, Grande L, Candela A, Porte RJ, Ghobrial RM, Isoniemi H, Schelde PB, Erhardtsen E, Klintmalm G, Emre S: Safety and efficacy of a single bolus administration of recombinant factor VIIa in liver transplantation due to chronic liver disease. Liver Transpl 2005;11:895900.

62 Lodge JP, Jonas S, Jones RM, Olausson M, Mir-Pallardo J, Soefelt S, Garcia-Valdecasas JC, McAlister V, Mirza DF: Efficacy and safety of repeated perioperative doses of recombinant factor VIIa in liver transplantation. Liver Transpl 2005;11:973-979. 